\title{
Soft tissue discrimination with contrast agents using micro-CT scanning
}

\author{
Emilie Descamps ${ }^{1}$, Alicja Sochacka ${ }^{1}$, Barbara De Kegel ${ }^{1}$, Denis Van Loo ${ }^{2,3}$, Luc \\ Van Hoorebeke ${ }^{2}$ \& Dominique Adriaens ${ }^{1, *}$
}

\footnotetext{
Research Group Evolutionary Morphology of Vertebrates, Ghent University, K.L. Ledeganckstraat 35, 9000 Gent, Belgium

2 UGCT, Department of Physics and Astronomy, Ghent University, Proeftuinstraat 86, 9000 Gent, Belgium

3 Department of Soil Management, Ghent University, Coupure Links 653, 9000 Gent, Belgium

* Corresponding author: dominique.adriaens@ugent.be
}

\begin{abstract}
The use of high resolution, three-dimensional visualization has been receiving growing interest within life sciences, with non-invasive imaging tools becoming more readily accessible. Although initially useful for visualizing mineralized tissues, recent developments are promising for studying soft tissues as well. Especially for micro-CT scanning, several X-ray contrast enhancers are performant in sufficiently contrasting soft tissue organ systems by a different attenuation strength of X-rays. Overall visualization of soft tissue organs has proven to be possible, although the tissue-specific capacities of these enhancers remain unclear. In this study, we tested several contrast agents for their usefulness to discriminate between tissue types and organs, using three model organisms (mouse, zebrafish and Xenopus). Specimens were stained with osmium tetroxide $\left(\mathrm{OsO}_{4)}\right.$, phosphomolybdic acid (PMA) and phosphotungstic acid (PTA), and were scanned using high resolution microtomography. The contrasting potentials between tissue types and organs are described based on volume renderings and virtual sections. In general, PTA and PMA appeared to allow better discrimination. Especially epithelial structures, cell-dense brain regions, liver, lung and blood could be easily distinguished. The PMA yielded the best results, allowing discrimination even at the level of cell layers. Our results show that those staining techniques combined with micro-CT imaging have good potential for use in future research in life sciences.
\end{abstract}

KEY WORDS: 3D visualization, micro-CT scanning, soft tissue, contrast agents, vertebrates

\section{INTRODUCTION}

Light microscopic histology is commonly used to analyze the organization and internal structure of biological tissues. However, despite its advantage in providing high resolution images, it requires elaborate preparation and full destruction of the specimen. It also often generates marked and heterogeneous distortions (JONES et al., 1994; CARDEN et al., 2003; DESCAMPS et al., 2012). To properly understand tissue organization, life sciences research in developmental biology or comparative biology currently requires accurate, high resolution three-dimensional (3D) imaging of these tissues within a whole organism topography. The latter has gained interest with the increasing development of valuable new automated imaging techniques, which facilitate visualization, processing and analysis of 3D images (see also ZANETTE et al., 2013). Those methods include $\mathrm{X}$-ray micro Computed Tomography $(\mu \mathrm{CT})$ scanning (MASSCHAELE et al., 2007; CNUDDE et al., 2011), magnetic resonance imaging (MRI) (TYSZKA et al., 2005; POHLMANN et al., 2007), Optical Projection Tomography (OPT) (SHARPE et al., 2002), absorption and phase-contrast synchrotron X-ray imaging (BETZ et al., 2007; BOISTEL et al., 2011) and Light Sheet (based) Fluorescence Microscopy (LSFM) (SANTI, 2011; BUYTAERT et al., 2012; DESCAMPS et al., 2012).

$\mu \mathrm{CT}$ scanning is the oldest tomographic imaging technique and most frequently applied to image $3 \mathrm{D}$ tissue organization in a noninvasive way (RITMAN, 2011). It allows the 
discrimination of soft from hard tissue, relying on the differences in photon attenuation levels of these tissue types (RITMAN, 2004; MizUTANI \& SUZUKI, 2012). Bone, with its calcium phosphate minerals, attenuates X-rays more intensely than the surrounding soft tissues (such as cartilage, nerves, blood vessels and muscles). As the latter are mainly composed of low-atomicnumber elements (carbon, hydrogen, oxygen), their comparable levels of hydration result in low contrast levels (MizUTANI \& SUZUKI, 2012). Although recent studies show that proper boundary conditions of tissue sampling (such as stabilized humid environment) allow contrast between some soft and hard tissues (NAVEH et al., 2014), a more detailed discrimination requires the use of contrast agents (high-atomicnumber elements) that bind to components of these soft tissues (MizUTANI et al., 2008; MEtSCHER, 2009a; MizUtANi \& SUZUKI, 2012; PAUWELS et al., 2013), or the use of phase contrast imaging (RITMAN, 2004; BETZ et al., 2007; MiZUTANI \& SUZUKI, 2012). As with the contrast agents used in transmission electron microscopy (TEM), these agents bind differently to soft tissue types in whole mount samples, thereby allowing $\mu \mathrm{CT}$ scanning to provide $3 \mathrm{D}$ data on soft tissue topography. Because of this potential, staining techniques with contrast enhancement agents have been tested for their ability to improve tissue discriminations and organ boundaries (DOBRIVOJEVIC et al., 2013). Soft tissue contrast agents that have been used on biological specimens include osmium, gold, silver, iodine, platinum, mercury, tungsten, molybdenum and lead (MIZUTANI \& SUZUKI, 2012; ZANETTE et al., 2013). Although some of these agents allow the visualization of particular tissues or cells (such as liposome-rich cells being contrasted with an iodinated contrast agent) (SCHAMBACH et al., 2010), other agents generate a more overall contrasting of certain tissue types (e.g. myelinated brain tissue versus grey matter) (EFIMOVA et al., 2013).

Studying the 3D organization of organs within an organism using $\mu \mathrm{CT}$ scanning particularly benefits from contrast agents that meet two criteria: (1) they can be administered in a simple manner by submersing complete specimens in an aqueous solution containing elements with a high atomic number, and (2) they penetrate easily through the thick layers of tissues (PAUWELS et al., 2013). If the agents could also be washed away after scanning, this would be an additional advantage in the study of internal structures of rare specimens, such as type material from collections. METSCHER (2009b) provided a first empirical approach to developing simple protocols for staining small but complete organisms, without using the toxic osmium tetroxide (a commonly used but highly toxic contrast agent for TEM). MizUTANI \& SUZUKI (2012) gave an overview of commonly-used contrast agents, and their general contrasting potentials. In a more extensive comparison of contrast agents that meet the first two criteria mentioned above, PAUWELS et al. (2013) compared the contrasting enhancement of 28 different chemicals on samples larger than $1 \mathrm{~cm}^{3}$. All three studies showed that the best contrasts are obtained by using aqueous solutions of osmium tetroxide $\left(\mathrm{OsO}_{4}\right)$, phosphomolybdenic (PMA) or phosphotungstic acid (PTA), or inorganic iodine (in different solutions). Whereas MizUTANI \& SUZUKI (2012) reviewed the features of these agents, as they are known from their application in TEM, METSCHER (2009a) provided overview images of reconstructed whole mount specimens. The latter author did indicate, among other things, that with PTA, cartilage matrix does not stain strongly. PAUWELS et al. (2013) compared the contrasting enhancement of muscle tissue versus adipose tissue, and tested penetration capacities of the contrast solutions. More recently, GIGNAC \& KLEY (2014) tested Lugol's iodine staining on larger specimens, to analyse its contrasting potential across different tissue types.

Although much progress has been made on the use of these contrast agents, and their application in $\mu \mathrm{CT}$ scanning has become common practice (ZANETTE et al., 2013), little is known about the binding affinities of these agents for particular tissues in large tissue blocks or whole organisms, and thus their potential to allow automated segmentation of individual organs or tissues based on voxel grey values. Applications of 
contrast-enhancing elements in TEM suggest that $\mathrm{OsO}_{4}$ labels lipids in cell membranes (CARSON \& HLADIK, 2009), and hence its application with $\mu \mathrm{CT}$ scanning should visualize all cells rather equally. Although this would theoretically make discrimination between cell types rather difficult, it has allowed discrimination between neural and vascular tissue (HALL et al., 1945; WATSON, 1958; HAYAT, 2000; AOYAGI et al., 2010; WATLING et al., 2010; MizUTANi \& SUZUKI, 2012). JoHNSON et al. (2006) showed that $\mathrm{OsO}_{4}$ allows different organs to be distinguished in early embryos, however, the discriminating power across different tissue types was not explored in detail. In adult mice, $\mathrm{OsO}_{4}$ proved to be suitable for visualizing tongue musculature, although only for smaller tissue specimens due to limited penetration (AOYAGI et al., 2013). PTA on the other hand is known to adhere to various proteins and is considered to be suitable for visualizing connective tissue (KIERNAN, 1981; MetsCher, 2009a). PMA allowed the identification of cartilage structures in mollusks (GOLDING \& JONES, 2007). Iodine is considered not to adhere to specific chemical components but rather uniformly to tissue constituents (MIZUTANI \& SUZUKI, 2012), although a binding affinity of iodine trimers to glycogen and lipids has been suggested (BOCK, 1972; METSCHER, 2009b). Also a higher affinity with liposomerich cells (BARON, 1994; SCHAMBACH et al., 2010), connective tissue of muscle fascia, individual muscle fibers (JEFFERY et al., 2011; TSAI \& HOLLIDAY, 2011; WILHELM et al., 2011; BAVERSTOCK et al., 2013), and blood has been suggested (DEGENHARDT et al., 2010). Still, METSCHER (2009b) indicated that, based on his experiments with embryos of both vertebrates and invertebrates, none of the contrast agents used $\left(\mathrm{OsO}_{4}\right.$, PTA and iodine solutions) was tissue-specific.

Some apparently conflicting, or rather inconsistent results regarding the tissuediscriminating potentials of these contrast agents thus remain, especially when applied to complete organisms. Because of that, we wanted to focus more on differences in contrasts between tissue types and organs, and compare the degrees to which tissue and organ boundaries can be discriminated. We compared the effect of $\mathrm{OsO}_{4}$, PTA and PMA using embryonic mice (stages E14.5 and E15.5), and contrasted that to a recently published similar test using Lugol's iodine staining (GIGNAC \& KLEY, 2014). More specifically, we tested whether $\mathrm{OsO}_{4}$ generates a non-discriminative contrast of all soft tissues, or whether some tissues can be discriminated consistently across the complete organism. As it has been claimed in literature that PTA, and PMA solutions have similar discriminative potentials to the highly toxic $\mathrm{OsO}_{4}$, we tested whether that was indeed the case at the level of tissue types. As the best results were obtained with PTA and PMA, we also compared them across other taxa, using a juvenile zebrafish and Xenopus tadpoles. With respect to PMA and PTA, if indeed they bind specifically to proteins, including collagen, we would expect protein-rich tissues (such as blood and muscle tissue) and dense connective tissues (such as the dermis, ligaments and tendons) to show higher levels of affinity with the contrast agents (and lower levels in, for example, cartilage, which is lower in protein levels). The potential of the different contrast agents to discriminate between myelinated and non-myelinated nerves was not tested in this study, as myelination in mice only starts at the E16.5 stage (thus later than the one studied here) (HARDY \& FRIEDRICH, 1996). As we used complete organisms exceeding $1 \mathrm{~cm}^{3}$, we tested whether these agents penetrate sufficiently to allow tissue discrimination throughout the whole body. This paper further discusses the different characteristics of each contrast agent, and describes how they could be applied for tissue differentiation and (semi-)automated segmentation when using $\mu \mathrm{CT}$ scanning.

\section{MATERIALS AND METHODS}

\section{Specimens}

We used five mice (Mus musculus), two tadpoles (Xenopus laevis) and one juvenile 
zebrafish (Danio rerio). The mice were obtained from the Department for Molecular Biomedical Research (DMBR) at the VIB and Ghent University (Belgium). The embryos were removed from the mother on embryonic day E14.5 (E15.5 for PMA-stained mouse), collected in phosphate-buffered saline (PBS) and fixed overnight in $4 \%$ paraformaldehyde at room temperature. The Xenopus laevis tadpoles were also reared at the DMBR, euthanized with an overdose of MS-222 (ethyl 3-aminobenzoate methanesulfonate salt, Sigma Aldrich, E10521) and fixed in 4\% paraformaldehyde in PBS at stage 48. The juvenile zebrafish was obtained through the commercial trade (Florida). It was euthanized with an overdose of MS-222 and fixed in 4\% paraformaldehyde. All experimental procedures were performed in accordance with the Experimental Animal Ethics Committee of Ghent University.

\section{Contrast stains}

Contrast agents were obtained from VWR International (PMA and PTA) and Laborimpex $\mathrm{NV}\left(\mathrm{OsO}_{4}\right)$. All mouse embryos $(n=5$, average total length: $\pm 10 \mathrm{~mm}$ ) were stained overnight (14 hours), except for the PMA mouse, which was stained for six days. The Xenopus tadpoles (average total length: $\pm 10 \mathrm{~mm}$ ) were stained with PTA for 24 hours and the juvenile zebrafish (total length: $22 \mathrm{~mm}$ ) was stained with PMA for six days. The staining times were chosen arbitrarily, but were sufficiently long to allow appropriate penetration. The protocols followed METSCHER (2009a), except for the PTA and PMA staining (PMA was not used by the latter). PTA and PMA staining was performed with $2.5 \%$ solution in demineralized water. The $\mathrm{OsO}_{4}$ staining was done in a $1 \%$ osmium tetroxide $\left(\mathrm{OsO}_{4}\right)$ solution.

\section{Micro-CT imaging}

The mouse and zebrafish specimens were kept in vials with a saturated atmosphere of ethanol vapour to prevent shrinkage from dehydration.
Although X-ray attenuation of water and ethanol is low, experience showed that better contrast results were obtained without the specimens being fully submerged. For the Xenopus tadpoles, to avoid specimen movement during acquisition of the $\mu \mathrm{CT}$ images, they were embedded in Epon (Fluka, 45359) (after dehydration in an ethanol series). The specimens were all scanned at the $\mu \mathrm{CT}$ scanning facilities of UGCT (Ghent University, Belgium). The setup consisted of a dual-head microfocus X-ray source (FeinFocus FXE160.51 transmission tube and FeinFocus FXE160.48 directional tube head), a high precision Micos UPR160 F Air rotation stage, an interchangeable detector and in-house-developed acquisition software (DIERICK et al., 2010). For these samples, only the Varian PaxScan 2520V and the PerkinElmer XRD 1620 CN3 CS a-Si flat panel detectors were used. For all scans, the transmission tube head was used. All mouse embryos, except the one stained with PMA, were scanned using a tube voltage and target current of $100 \mathrm{kV}$ and $60 \mu \mathrm{A}$, respectively. For each individual, a series of 1001 projections with an exposure time of one second per projection was recorded using the Varian detector and covering 360 degrees, resulting in voxel sizes of $5.95 \mu \mathrm{m}$ (each dimension of the isometric voxels). The PMA-stained mouse was scanned at $100 \mathrm{kV}$ and $90 \mu \mathrm{A}$, using the PerkinElmer detector. A series of 1441 projection images was recorded at an exposure time of two seconds per projection image, covering 360 degrees resulting in voxel sizes of $6.24 \mu \mathrm{m}$. Identical settings were used for the juvenile zebrafish allowing a better comparison between the two PMA-stained specimens. The voxel sizes for the zebrafish were $5.82 \mu \mathrm{m}$. For the Xenopus tadpole, the X-ray tube was operated at $80 \mathrm{kV}$ tube voltage and $37.5 \mu \mathrm{A}$ target current. Using the PerkinElmer detector, a total of 1001 projection images was recorded at a total exposure time of 6 seconds per image, covering 360 degrees and resulting in voxel sizes of $3.40 \mu \mathrm{m}$. Reconstruction of the tomographic projection data was performed using the in-house-developed CT-software Octopus (VLASSENBROECK et al., 2007) and VGStudioMAX. 


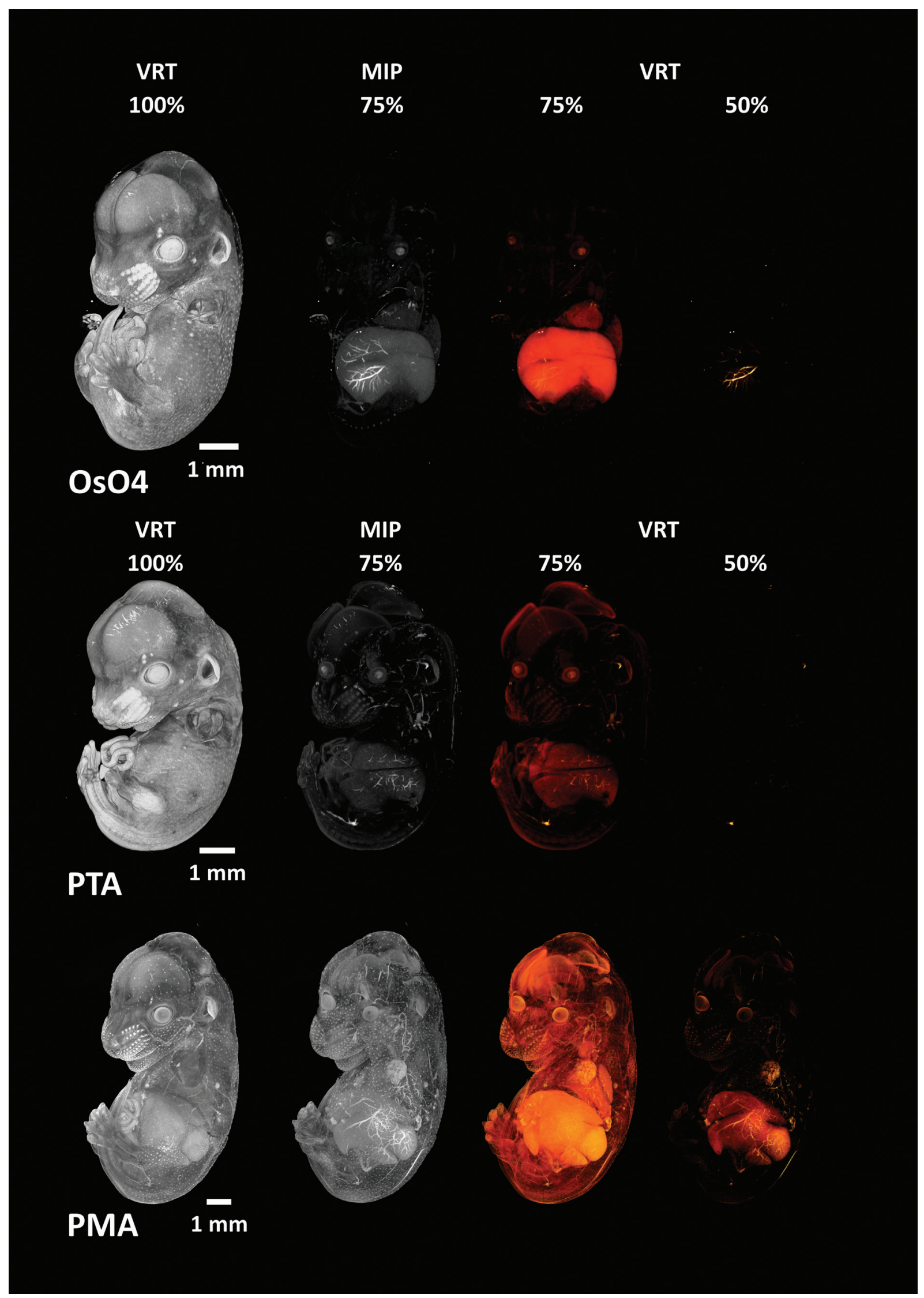

Fig. 1. - Volume rendering images of the mouse embryos stained with three different contrast agents, using maximum intensity projection (MIP) and texture volume rendering (VRT) at $100 \%$ (left), $75 \%$ and $50 \%$ of the total color value range $\left(\mathrm{OsO}_{4}\right.$ - osmiumtetroxide, PTA - phosphotungstic acid, PMA - phosphomolybdenic acid). 


\section{Image analysis}

The TIFF virtual images were imported in the software Amira (version 5.5.0, 64-bit, Mercury Computer Systems). Volume rendering (Volren) of the total color value range was performed. To visualize an overview of the level of discrimination between tissue types and organs, volume rendering images were generated where the lower threshold was set to $50 \%$ and $75 \%$ of the total color range of the tissues, allowing a qualitative comparison across contrast stains within the mouse embryos (Fig. 1), and across the species (Fig. 2). As this is an arbitrary manner of setting thresholds, these figures should not be considered in any quantitative way but purely for visualization of overall results. These were visualized using the texture-rendering option
(VRT), whereas the $75 \%$ threshold was also visualized using maximum intensity projection (MIP). The latter has proven to be more accurate for visualizing the vasculature than texture-based volume rendering (RUBIN et al., 1994; FISHMAN et al., 2006). Virtual slices (sagittal and frontal) were generated at similar anatomical positions in the three mouse embryos for a more detailed comparison across the three contrast agents (Fig. 3). For a more detailed visualization of organ discrimination, volume rendering images (using VRT) and virtual cross sections were generated of specific regions of interest (Figs 4-7). Where pixels were rather coarse on these virtual sections, a low pass filter was applied for improved visualization. For the anatomical nomenclature, we used on-line and published databases on mouse brain anatomy (SCHAMBRA,

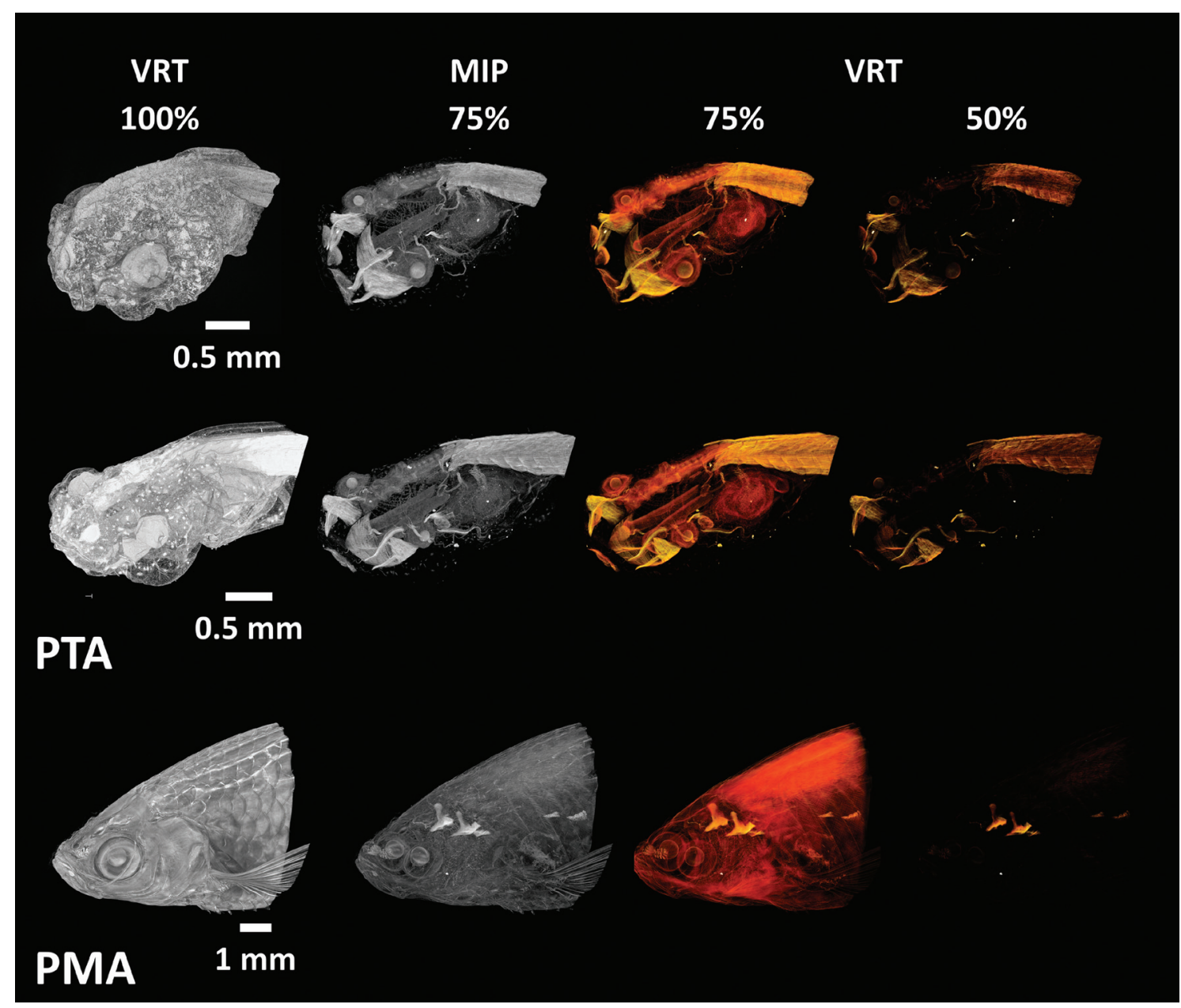

Fig. 2. - Volume rendering images of Xenopus laevis tadpoles (upper two rows) stained with PTA and juvenile zebrafish (Danio rerio) stained with PMA, using maximum intensity projection (MIP) and texture volume rendering (VRT) at $100 \%$ (left), $75 \%$ and $50 \%$ of the total color value range (PTA - phosphotungstic acid, PMA - phosphomolybdenic acid). 
2008; ALlEN INSTITUTE FOR BRAIN SCIENCE, 2014), zebrafish brain (WULLIMANN et al., 1996; ULLMANN et al., 2010) and vascular anatomy (IsOGAI et al., 2001), and Xenopus anatomy (WIECHMANN \& WIRSIG-WIECHMANN, 2003).

\section{RESULTS}

\section{Overall staining patterns}

A difference in the overall contrast between voxel color values for the tissue types and organs could be observed (Figs 1-3). While the voxel size of the PMA-stained mouse embryo was the highest of all $(6.24 \mu \mathrm{m}$ vs 5.95$)$, the quality of the virtual sections was substantially better. The arbitrary thresholds of a $75 \%$ color value range showed that for PMA, most organs were still stained, whereas for PTA and $\mathrm{OsO}_{4}$, hardly any structures were visible (Fig. 1). At the 50\% color value range, only PMA allowed the visualization of multiple organs. In all stains, the liver seemed to absorb the highest levels of contrast agents. MIP-rendering allowed better visualization of tissues that had higher color intensities, especially for blood within the blood vessels. This allowed clearer visualization of the vascularization of the liver with all stains.

In the zebrafish and Xenopus tadpoles, overall staining patterns in relation to the $75 \%$ and $50 \%$ thresholds were somewhat different (Fig. 2). For the PTA-stained tadpoles, several organs were clearly visible even at the $50 \%$ threshold, especially muscle tissue and eye lenses. For the

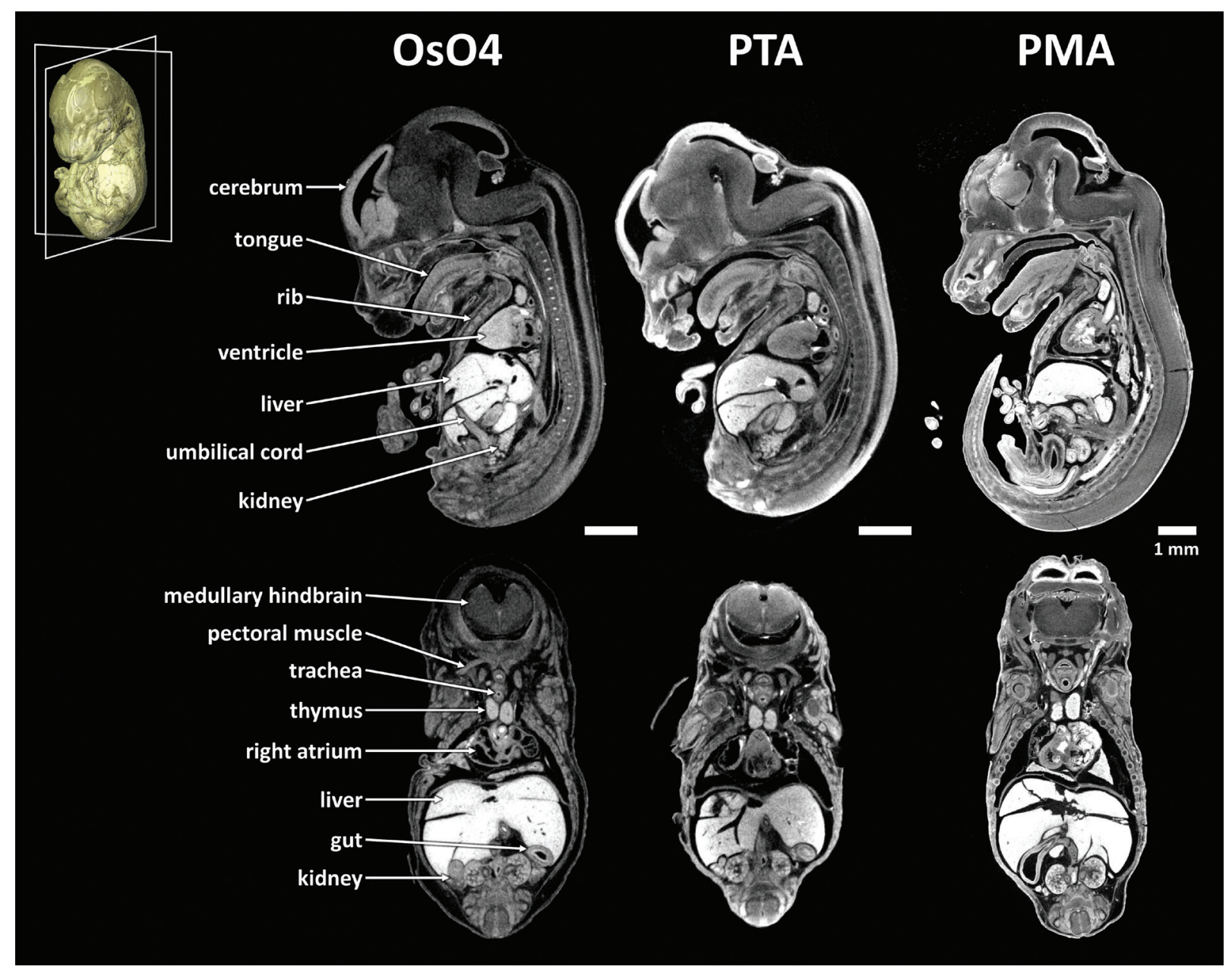

Fig. 3. - Virtual sagittal (top) and frontal (bottom) sections at similar position in the mouse embryos stained with three different contrast agents $\left(\mathrm{OsO}_{4}-\right.$ osmiumtetroxide, $\mathrm{PTA}$ - phosphotungstic acid, PMA - phosphomolybdenic acid). Inset shows the relative position of the sections. 
PMA-stained zebrafish, on the other hand, hardly any structure was visible at the 50\% threshold, only condensations of blood in cranial sinuses.

\section{Discrimination of tissue types and organs}

An overview of the tissue types and organs that could clearly be distinguished with each of the contrast agents is given in Tables 1 and 2 .

\section{$\mathrm{OsO}_{4}$}

In the mouse embryos, structures that were most intensely stained were the eye lenses, liver, heart, lungs (small cavities were visible, suggesting bronchioli were present, together with bronchi and trachea), thymus and blood (Figs 1, $3,4)$. Also part of the intervertebral discs, more specifically the nucleus pulposus, seemed to be intensely stained (Fig. 4B). In most cases, not only the blood but also the actual blood vessels and the heart were clearly visible in the virtual sections (Fig. 4A). What seemed to be glomeruli in the metanephros were clearly visible, as well as the adrenal gland next to the kidney (Fig. 4A). This higher intensity of the voxel values could be the consequence of an increased vascularization and thus merely demonstrate presence of blood rather than higher affinities for these tissues. Virtual sections showed that penetration of the stain was homogenous, as centrally-located organs were clearly identifiable (Figs 3, 4A). As is the case for most other contrast agents, $\mathrm{OsO}_{4}$ stained epithelial structures very well (e.g. olfactory epithelium, follicles of the vibrissae, and the gut and tracheal mucosa). In the brain, particular regions (such as the cerebral periventricular layers, mammillary mantle zone and the trigeminal ganglion) could be discerned. Of the musculoskeletal system, cartilage (e.g.

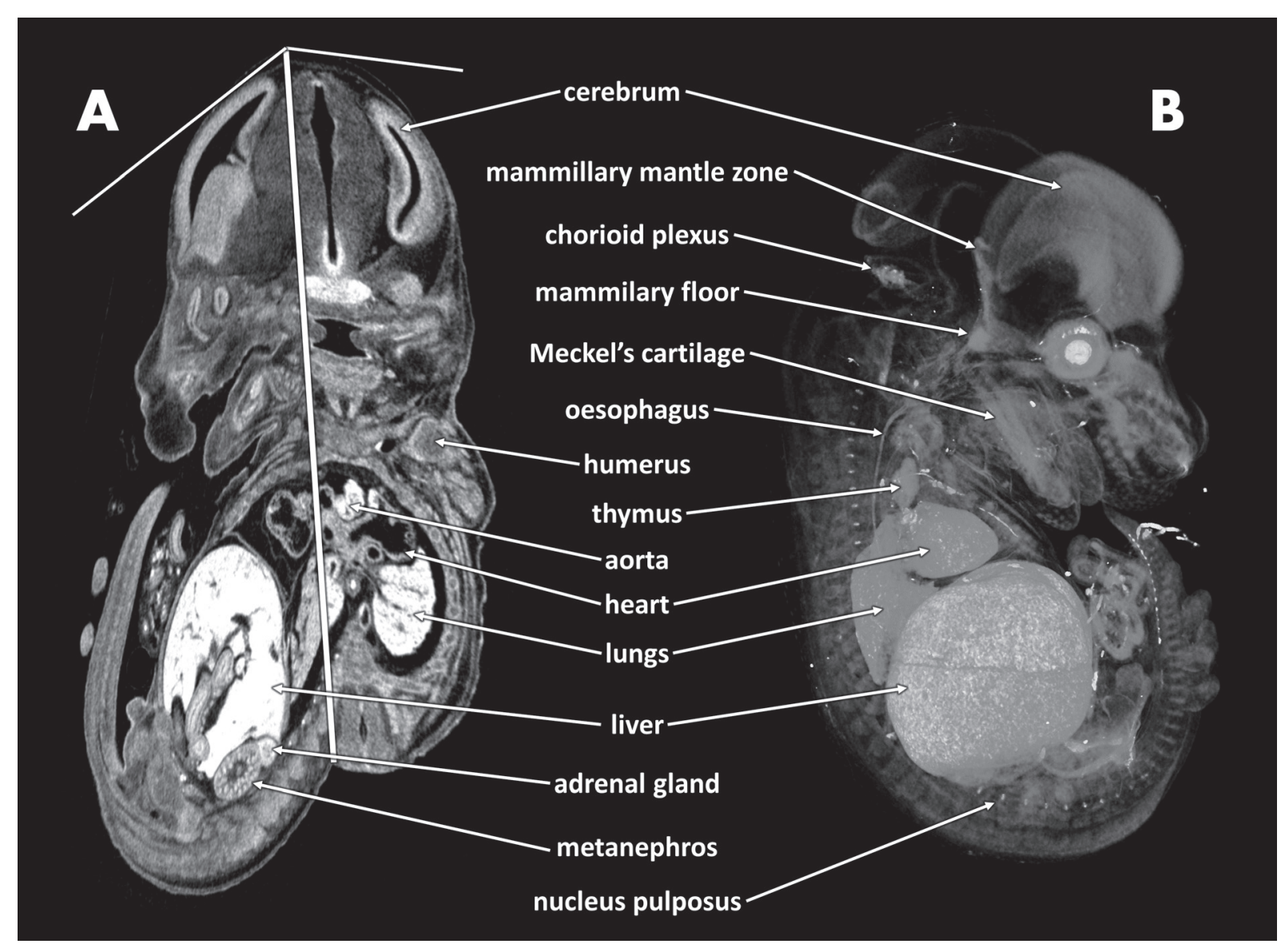

Fig. 4. - Organ and tissue specific voxel intensities of mouse embryo (stage E14.5) stained with osmiumtetroxide: (A) virtual frontal and parasagittal section and (B) volume rendering image (right lateral view). 


\section{TABLE 1}

Summary of the published binding preferences of contrast agents and the level of visualization obtained in this study.

\begin{tabular}{|c|c|c|}
\hline $\begin{array}{l}\text { Contrast } \\
\text { agent }\end{array}$ & Binding preference & Visualised soft tissue structures \\
\hline $\mathrm{OsO}_{4}$ & $\begin{array}{l}\text { Lipids, proteins and nucleic } \\
\text { acids }\end{array}$ & $\begin{array}{l}\text { Eye lens, liver, heart, lungs, thymus, blood and blood } \\
\text { vessels, metanephros, adrenal gland, nucleus pulposus, } \\
\text { epithelia, cell dense brain regions, muscle, cartilage }\end{array}$ \\
\hline PTA & Connective tissue (collagen) & $\begin{array}{l}\text { Eye lens, liver, heart, lungs, thymus, blood, blood } \\
\text { vessels, metanephros, epithelia, glands, cell dense brain } \\
\text { regions, muscle, cartilage }\end{array}$ \\
\hline PMA & Collagen (phospholipids?) & $\begin{array}{l}\text { Eye retina, liver, lungs, thymus, blood and blood } \\
\text { vessels, metanephros, epithelia, glands, cell dense brain } \\
\text { regions, muscle, cartilage }\end{array}$ \\
\hline
\end{tabular}

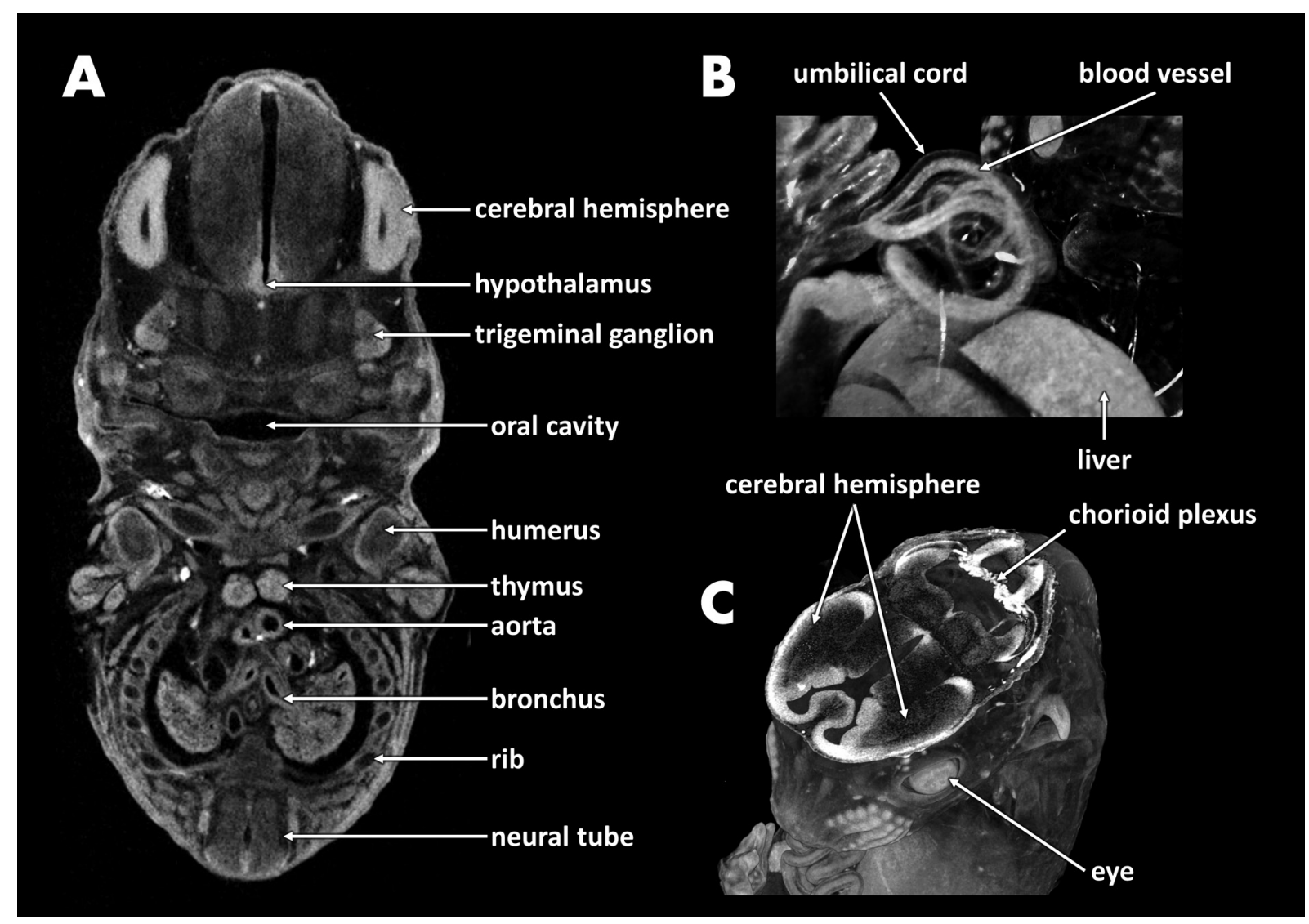

Fig. 5. - Organ and tissue specific voxel intensities of mouse embryo (stage E14.5) stained with phosphotungstic acid: (A) virtual frontal section at similar level as in Fig. 4, (B) volume rendering image of the umbilical region, and $(\mathrm{C})$ cut through volume rendering through the brain. 


\section{TABLE 2}

Overview of the tissue and/or organ specificity of the contrast agents used in this study ('- ' indicates hardly visible, ' + ' indicates weak discrimination potential, ' ++ ' and ' +++ ' indicate moderate and very good discrimination potential, respectively).

\begin{tabular}{|l|c|c|c|}
\hline \multicolumn{1}{|c|}{ Tissue/Organ } & OsO $_{4}$ & PTA & PMA \\
\hline Cartilage & + & + & ++ \\
\hline Muscles & ++ & ++ & +++ \\
\hline Blood/vessels & ++ & ++ & ++ \\
\hline Liver & +++ & +++ & +++ \\
\hline Eye/eye lens & ++ & +++ & +++ \\
\hline Epithelial structures & ++ & +++ & +++ \\
\hline Cell-dense nervous tissue & +++ & +++ & +++ \\
\hline Lungs & +++ & +++ & +++ \\
\hline Connective tissues & ++ & ++ & ++ \\
\hline
\end{tabular}

Meckel's cartilage) and muscle tissue could be distinguished (Fig. 4B). Ossification zones, as observed with the other stains, could not be discerned with $\mathrm{OsO}_{4}$.

\section{PTA}

Tissues or organs that showed the highest color intensities in the mouse embryo were eye lenses, liver, blood, and epithelial structures (olfactory epithelium, follicles of vibrissae) (Figs 1, 2, 5). Some parts of the brain showed higher levels of $\mathrm{X}$-ray attenuation, such as the periventricular layers of the cerebral hemispheres, the trigeminal ganglion and the hypothalamus (Fig. 5A). The myelencephalic chorioid plexus was intensely stained, which could be due to the staining of the blood it contained (Fig. 5C). Postcranially, spinal ganglia were visible. In general, blood showed highest intensities on the virtual sections, and blood vessels could be distinguished (e.g. the umbilical vessels embedded within the umbilical cord, leaving the mucoid tissue poorly stained) (Fig. 5B). Other organs that were clearly visible were the thymus, lungs (trachea, bronchi, bronchioli), kidney (glomeruli were visible) and adrenal gland. Of the musculoskeletal system, cartilage and muscles (e.g. eye muscles) were visible. Cartilage of ribs and limbs could be clearly discriminated, whereas the contrast between vertebral cartilages and surrounding tissues was less prominent. The presence of ossifications (which arise at about this E14.5 stage) could be derived from the differences in the grey value intensity of the cartilage matrix. At locations where ossification was to be expected, cartilage matrix was stained less (e.g. base of scapula, upper half of humeral diaphysis, proximal parts of ribs) (PATTON \& KAUFMAN, 1995; MA et al., 2003).

In the PTA-stained tadpoles, contrasts between the different tissue types was consistent between the two specimens analyzed (Fig. 2). As in the mouse embryos, muscles (individual fibers and myosepta), eye lenses (superficial layer), blood and blood vessels (including the heart tissue), epithelia (olfactory epithelium, gill and gut mucosa) and the brain were more intensely stained (Fig. 6). However, discrimination between specific brain regions was not as clear as in the mouse embryos. Also discernible were the mucosal layers of the filtering plates, which comprise a central portion of connective tissue, covered by one or two layers of epithelial cells covered by mucus (BRUNELLI et al., 2004) (Fig. $6 \mathrm{C})$. The thick oral plates were intensely stained 
(Fig. 6D). Cartilage could be distinguished as the perichondral connective tissue was visible, as well as what appeared to be individual chondrocytes (Fig. 6C, inset). In the notochord, the cell membranes of notochordal cells could also be discerned on the virtual sections.

\section{PMA}

In the mouse embryo, the brightest structures were the eyes (retina only), the liver, particular brain regions (such as the inferior colliculus, mammillary mantle zone, periventricular layers of the cerebral hemispheres) (Figs 1, 7A), blood and blood vessels, lungs (with distinct bronchioli), epithelia (olfactory, tracheal and gut mucosa, epidermis with follicles of vibrissae and regular hair), and muscles (including the heart) (Figs 1, 7). In addition, several glandular structures could be clearly distinguished, such as the thymus, salivary glands, adrenal gland (Fig. 7A), and the pancreas. Distinct from the other contrast agents, in the eye, PMA stained only the photoreceptor layer intensely, whereas the lens and optic nerve were clearly less stained (Fig. 7B, C).

Cartilaginous structures were also stained, although it was not clear whether chondrocytes or the matrix were the brighter on the $\mathrm{CT}$ sections. Also here, we could distinguish cartilage that had started to become ossified (based on the topography of suspected ossification), whereas for PMA there were cartilaginous regions where the matrix was not stained or was poorly stained (Fig. 7D). Whether this corresponds to resorbed cartilage or not, could not be verified here. It

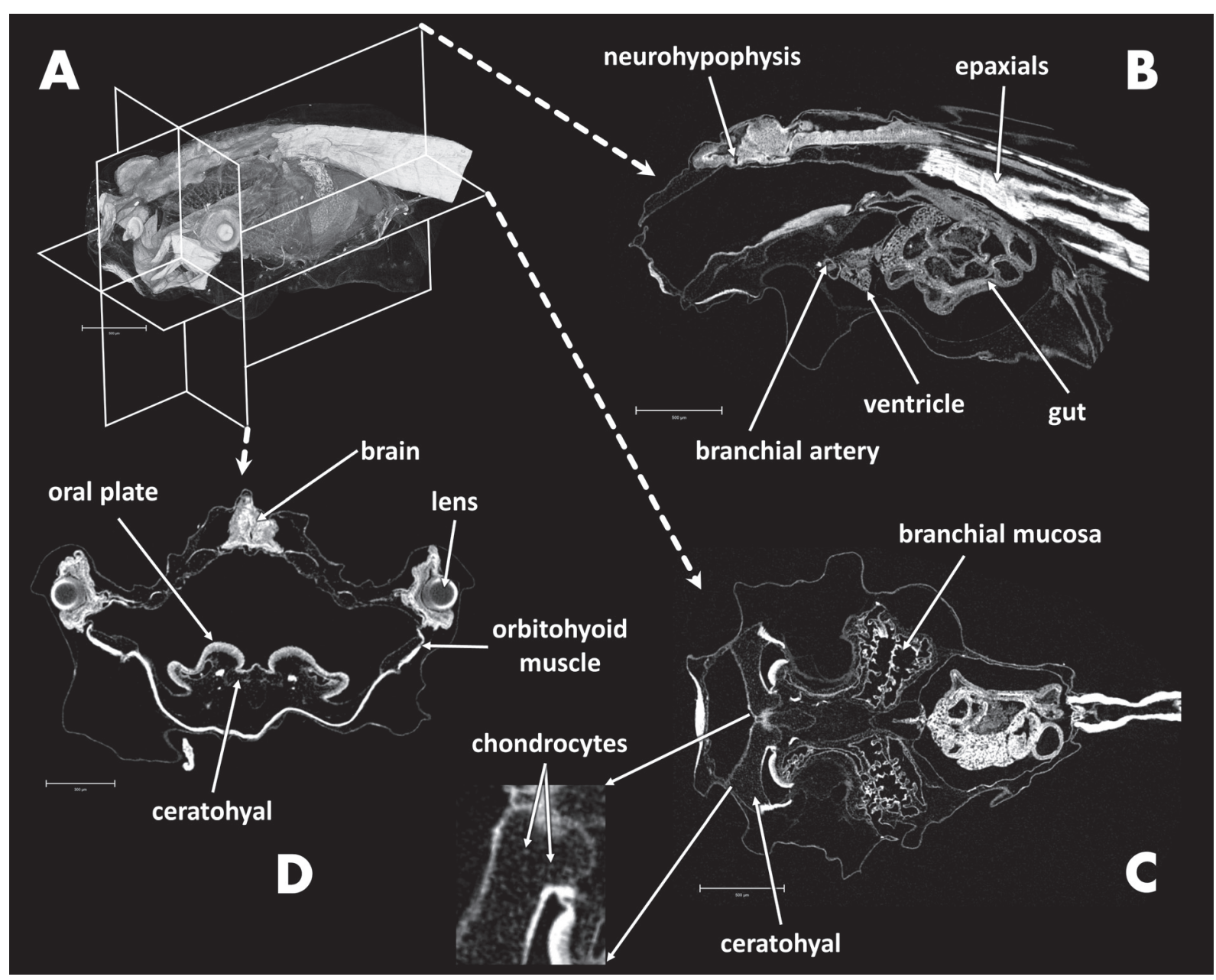

Fig. 6. - Organ and tissue specific voxel intensities of Xenopus laevis tadpole (stage 48) stained with phosphotungstic acid: (A) volume rendered overview, (B) mediosagittal virtual section, (C) horizontal virtual section through the ceratohyal cartilages, and (D) transverse section through the eye lenses. 
may be that the thin, but more intensely-stained superficial layer surrounding the darker cartilage corresponds to bone, whereas the layer in the same position around other cartilage corresponds to perichondrium (where this layer is thicker and less demarcated) (Fig. 7D).

Similar, highly qualitative results were obtained in the zebrafish juvenile (Fig. 8). Most spectacular results involved the level of detail in some organs and tissues. As in the mouse embryos, it was not the eye lens and eye nerve that were stained the most, but the remaining parts. It was even possible to distinguish all cellular layers of the retina (Fig. 8B, C). Blood also stained most intensely, visualizing the cranial sinuses in the specimen studied (Fig. 2). The keratinized pharyngeal pads were also clearly visible (Fig. 8A, E). Individual muscle fibers and myosepta were very clearly distinguishable (Fig. 8A, D). In the vertebral column, the notochord and its notochordal strand were obvious (Fig. 8A). In the brain, functional parts (rather than just layers) could be distinguished, of which some clearly stained more intensely (e.g. periventricular grey zone and torus longitudinalis of the optic tectum, eminentia granularis, intermediate thalamic nucleus, corpus cerebelli, medial octavolateralis nucleus, pituitary, etc.) (Fig. 8E). Bone could be distinguished, whereas cartilage was less obvious than in the mouse embryos. The hemibranchs appeared clearly as well (Fig. 8E). In the ventral branchial region, individual follicles of the thyroid gland were intensely stained (Fig. 8E).

\section{DISCUSSION}

\section{Limited contrast between tissue types and organs with $\mathrm{OsO}_{4}$ ?}

$\mathrm{OsO}_{4}$ is a highly toxic contrast agent interacting with unsaturated lipids, sometimes also interacting with proteins (WIGGLESWORTH,

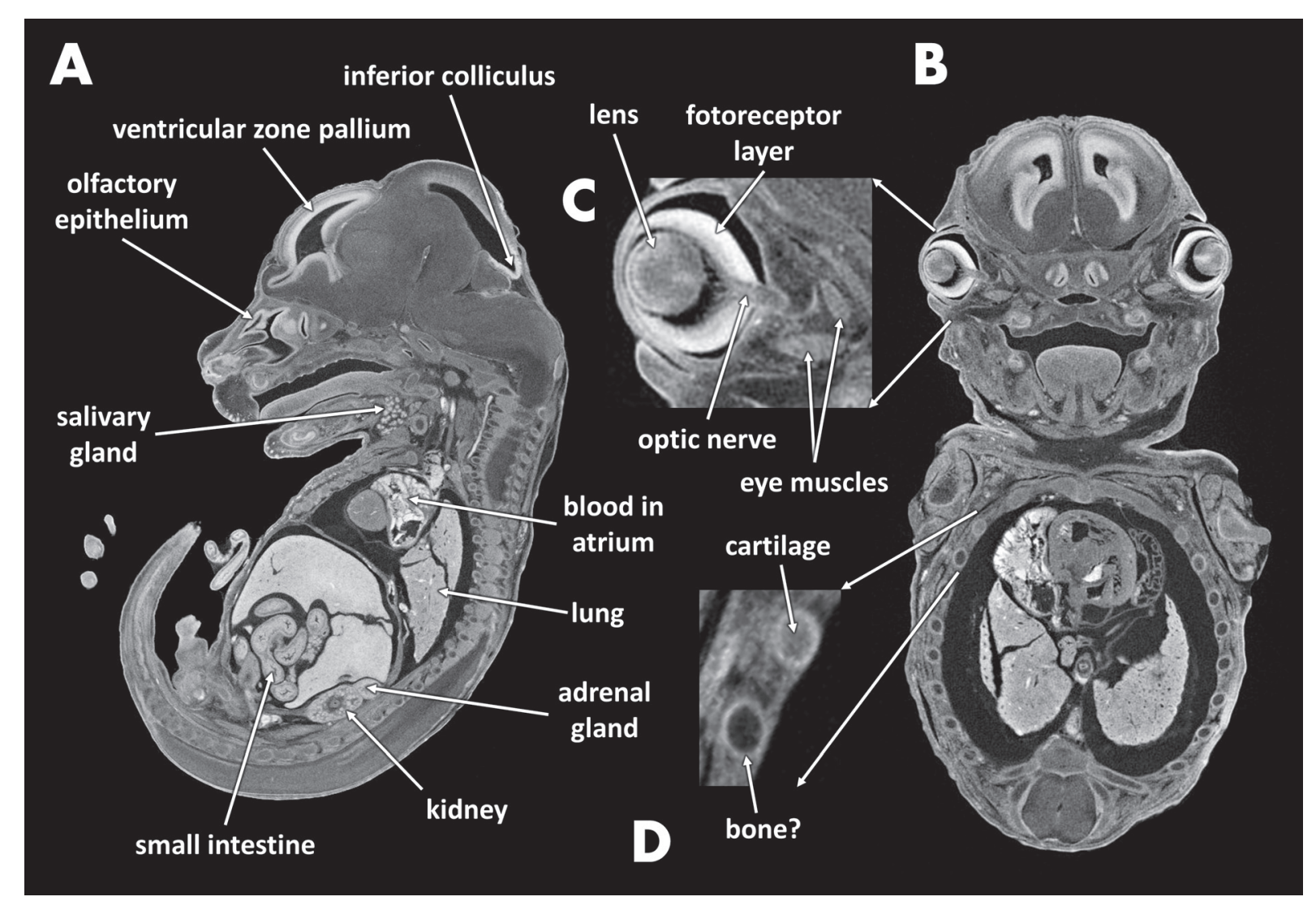

Fig. 7.-Organ and tissue specific voxel intensities ofmouse embryo (stage E15.5) stained with phosphomolybdenic acid: (A) virtual sagittal section through the kidney, (B) virtual frontal section through the optic nerves, (C) detail of the section at the eye, and (D) detail of the section at the ribs. 


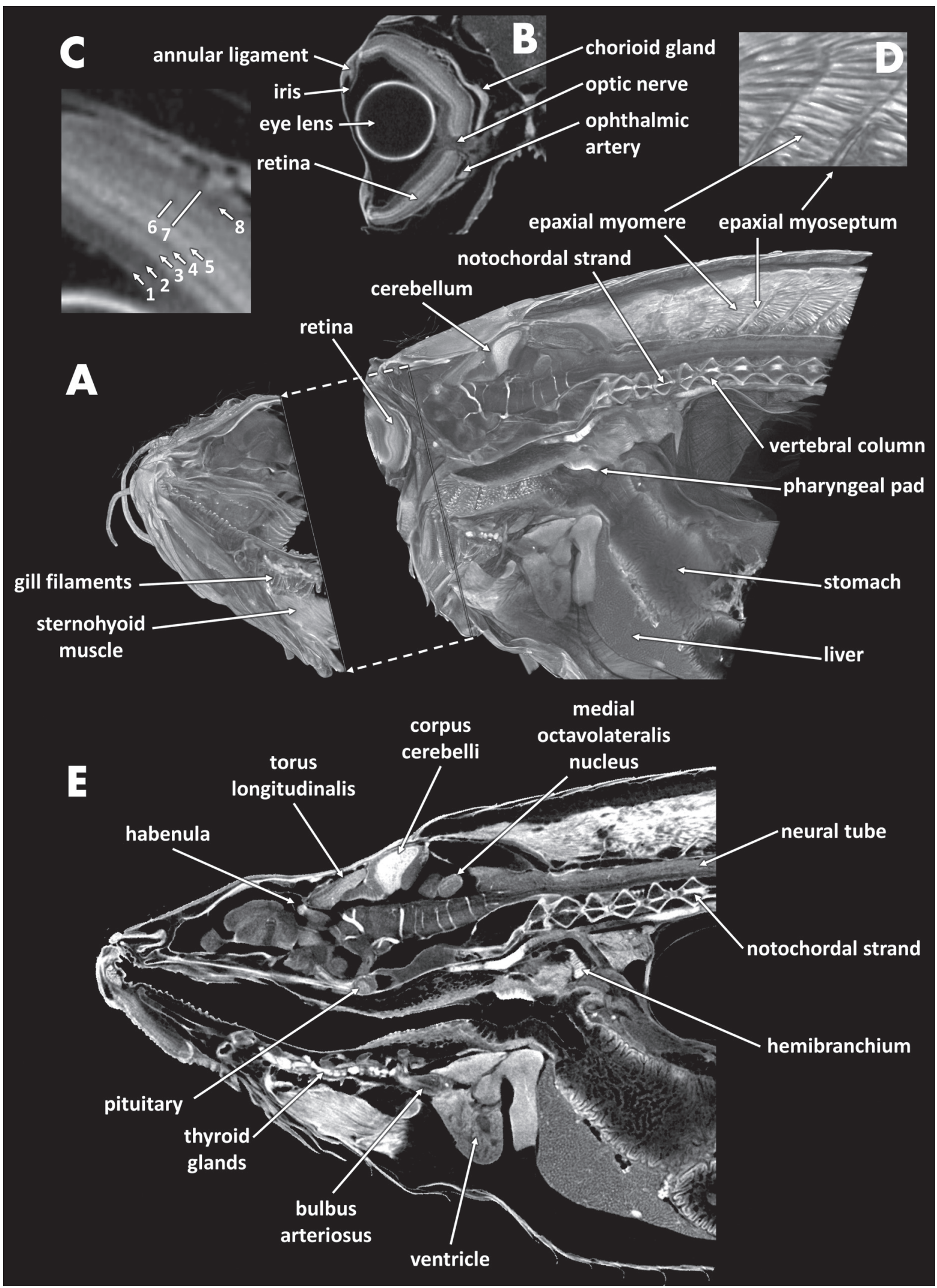

Fig. 8. - Organ and tissue specific voxel intensities of juvenile zebrafish stained with phosphomolybdenic acid: (A) volume rendering with mediosagittal cut-through and transverse cut-through at the level of the eyes, (B) detail of the eye, (C) higher detail of the retinal layers, (D) detail of epaxial muscle fibers and myosepta, (E) virtual mediosagittal section (Legend for Fig. C: 1 - ganglionic layer, 2 - inner plexiform layer, 3 - inner nuclear layer, 4 - outer plexiform layer, 5 - outer nuclear layer, 6 - cones photoreceptor layer, 7 - rods photoreceptor layer, 8 -pigmented layer). 
1975; HAYAT, 2000; DI SCIPIO et al., 2008). As such, a staining with limited contrast in grey values of the voxels across the tissue types and organs was expected, as $\mathrm{OsO}_{4}$ was expected to show an overall and similar affinity with all cell types (i.e. the phospholipids in their membranes). However, the overall result of the $\mathrm{OsO}_{4}$-stained mouse embryos was fairly good, allowing the discrimination of most tissues and organs (e.g. liver, blood, eye lens, heart, lungs, thymus). The intense staining of the liver, as was observed by JOHNSON et al. (2006), could be explained by its rich content in lipids and lipoproteins. The intense affinity with blood also confirms our hypothesis, i.e. that erythrocytes have high $\mathrm{OsO}_{4}$ affinity through their combined high protein (hemoglobin) and phospholipid content (enucleated cells with few organelles).

As with the other contrast agents, there was a non-homogenous visualization of blood vessels, and in several cases even a distinct unilateral difference in staining intensity. This asymmetry was not seen in other structures. This indicates that the blood, and not the blood vessels, stained intensely (as was expected), as postmortem precipitation of red blood cells due to gravity may explain the observed patterns.

Discrimination between particular brain regions was possible, partly due to the vascularization conditions (e.g. chorioid plexus). On the other hand, the intense staining of the periventricular strata in the dorsal telencephalic pallium (which was a consistent observation across the contrast agents used) requires an alternative explanation. Because myelin is phospholipid-dense, $\mathrm{OsO}_{4}$ is known to bind intensely to it (DI ScIPIO et al., 2008). In mouse embryos, however, myelin only starts to be produced by oligodendrocytes from the E16.5 stage on (we used E14.5 and E15.5 stages ) (HARDY \& FRIEDRICH, 1996). Still, the virtual sections gave similar results to histological sections stained with haematoxylin with respect to nuclear-dense versus less-dense zones (SCHAMBRA, 2008). Haematoxylin is known to stain nuclei due to its affinity with nucleic acids. The fact that the telencephalic periventricular zone is a cell-dense area where cell proliferation takes place, may then explain its intense staining with $\mathrm{OsO}_{4}$ (SEKI et al., 2011; ALLEN INSTITUTE FOR BRAIN SCIENCE, 2014). This seems to be confirmed by similar observations in brain regions of the other stained embryos, as well as the zebrafish.

The lung tissue also stained intensely, which could be explained by the glycoproteincontaining mucus, as well as the surfactant (a phospholipid-protein complex) (BATENBURG \& HAAGSMAN, 1998). However, lung surfactant production only starts around stage E17 in fetal mice (CONDON et al., 2004), whereas alveoli are formed from the E18.5 stage on (WARBURTON et al., 2010). As such, the observed cavities embedded within the lung tissue most likely represent bronchioles.

Additional structures that could be demarcated after $\mathrm{OsO}_{4}$ staining were epithelial tissues, muscles and cartilaginous elements (e.g. the observed Meckel's cartilage and ribs) (Fig. 4). We hypothesized that cartilage would not stain well, considering it is less dense in proteins or phospholipids. However, cartilage does contain a variety of proteoglycans in its matrix, of which the protein content is high (KNUDSON \& KNUDSON, 2001), and the matrix contains lipids (STOCKWELL, 1979). Both the glycosaminoglycans (components of the proteoglycans) and lipids might explain the moderate affinity for $\mathrm{OsO}_{4}$.

\section{Tissue/organ discriminative potentials of $\mathrm{OsO}_{4}$ compared to that of non-toxic alternatives}

As Metscher (2009a) indicated, other contrast agents can replace the toxic $\mathrm{OsO}_{4}$ and still give similar or even better results. Prior to the comparison of these agents in our study, we needed to consider some differences in the procedures of staining and $\mathrm{CT}$ scanning of the PMA mouse embryo (compared to the other mouse embryos). Firstly, the incubation period was longer (six days for the PMA embryo versus 
14 hours for the other embryos), and the amount of photonic data (photon statistics) per voxel was substantially higher (due to longer exposure time and higher $\mu$ A values). This implies that for each voxel, a higher rate of photonic data can be gathered during the scan, which could explain the apparently better quality of the virtual sections through the PMA mouse, even though absolute voxel resolution was similar (more photonic data per voxel reduces the amount of noise compared to the actual voxel value). This could explain why, within the same organ, the quality in these sections was better for the PMA dataset (Fig. 3). However, this does not explain the substantially higher discriminative power between the different tissue types and organs, which could then be explained by the longer incubation time and very likely the better contrast staining of PMA. As a result, from our study we cannot draw any quantitatively-supported conclusions on that, but only report that PMA clearly shows indications of being qualitatively better able to discriminate between tissue types and organs (also see below on the penetration aspects of the agents).

Comparing the results of $\mathrm{OsO}_{4}$ with those of PTA and PMA, several similarities could be observed. For all agents, it was the liver, blood, lungs, cell-dense brain regions and epithelial structures that showed the most intense staining. Also other organs such as the heart, cartilages, muscles, thymus, etc. could be discriminated, albeit with a lower intensity. In the PTA and PMA embryos, the cartilage regions undergoing ossification could be distinguished (darker central matrix of the cartilaginous structures), which was not the case for the $\mathrm{OsO}_{4}$ mouse (Fig. 7D).

However, there were also some marked differences with the $\mathrm{OsO}_{4}$ staining. PTA stained epithelial lining in a rather consistent way, and olfactory epithelium, integumentary, respiratory and digestive epithelia (both for the mouse embryos as for the Xenopus tadpoles) were intensely stained. GIGNAC \& KLEY (2014) showed that Lugol's iodine also has a higher affinity for epithelial tissue. Muscle tissue was stained with high intensity in the Xenopus tadpoles, which was not the case in the mouse embryos (Figs 5B, 6). We hypothesized that a high protein content of muscle tissue (densely-packed myofilaments) would result in highly-contrasted muscle tissue. In both the tadpoles and zebrafish, muscle fibers were clearly differentiated. In mice, however, differentiation of myotubules into myofibres only starts from the $19^{\text {th }}$ day of gestation on (WIRSÉN \& LARSSON, 1964). As such, myofilament density in E14.5 and E15.5 embryos would have been low, which could explain the relatively lower intensity of the involved voxels. Muscle tissue also stains intensely with iodine, as shown in literature (COX \& JEFFERY, 2011; JEFFERY et al., 2011; GignaC \& KLEY, 2014). The latter study even suggested that it can enable distinction between red and white muscle tissue, based on different carbohydrate contents.

Cartilaginous structures stained weakly, although cartilage is a connective tissue composed of, among other substances, collagen fibrils. A previous histochemical study already showed a similar outcome after PTA was added to sections comprising cartilage (QUINTARELLI et al., 1971). They suggested that the intensity of staining of cartilage with PTA decreases with a progressive increase in hydrogen-ion concentration of the PTA dye bath. PMA gave a much broader voxel intensity range, which yielded images that showed a high contrasting resolution between tissues, better than for all the other agents (Fig. 7). This was even more pronounced in the juvenile zebrafish, where, for example, details at the level of retinal cell layers could be discerned (Fig. 8B, C). The observed pattern may reflect distinct distributions of phospholipid densities in these layers (RoY et al., 2011). Also epithelial lining of the digestive and respiratory system was more pronounced in the mouse embryos, including now also the distinction of glandular epithelia (e.g. salivary gland). Whether the gland content or its epithelial lining was more intensely stained could not be verified here, however. It can also not be excluded that the glands were only visible in the PMA embryo, which was at the E15.5 stage (at which salivary glands become canalized 
with proliferating epithelial cells), whereas the other embryos were at the E14.5 stage (where the glands are still solid, multilobular glands) (TUCKER, 2007). Also in the zebrafish, thyroid glands could be observed (Fig. 7E). Another similarity with the $\mathrm{OsO}_{4}$ staining was that in the PMA zebrafish brain, brain regions that were cell-rich stained more intensely (e.g. central part of the corpus cerebelli) (CHENG, 2013). This confirms the above conclusion that it is not myelin itself that was visualized in the $\mathrm{OsO}_{4}$ mouse embryo, but brain cell nuclei. This is in contrast to the study by GIGNAC \& KLEY (2014), who could clearly distinguish myelinated from non-myelinated fibers in American alligators stained with Lugol's iodine. JEFFERY et al. (2011) reported that this Lugol's iodine preferentially binds to connective tissues surrounding the muscle fibers and suggested that iodine binds to glycogen molecules in the muscle cells. Glycogen has indeed a high iodine-binding capacity, yielding a glycogen-iodine complex (LECKER et al., 1997). Also ethanol solutions of iodine $\left(\mathrm{I}_{2} \mathrm{E}\right)$ showed a strong staining of muscle tissue in insects, allowing the visualization of individual muscle fibers (METSCHER, 2009a; WILHELM et al., 2011).

Although PMA and PTA allowed better discrimination between tissue types and organs based on voxel grey values, $\mathrm{OsO}_{4}$ still proved to be sufficiently powerful to distinguish and demarcate most of the organs based on their topography within the body and spatial relation to surrounding organs. As this study was not a quantitative analysis of contrast variation in voxel intensity values (as was done by GIGNAC \& KLEY, 2014), the assessment of the quality of contrast staining is based on the combination of voxel contrast and topographic anatomy. This is essential to anatomists who need to interpret 3D soft anatomy using CT data. Still, higher voxel contrasts can be especially useful for automated segmentation of tissue types or organs based on grey value thresholds.

\section{Consistent tissue/organ discrimination of PMA and PTA?}

Both PTA and PMA yielded excellent contrast between different tissues in the mouse embryo, as well as in the Xenopus tadpole and zebrafish, although the PMA results were superior (see above).

Tungsten is known to specifically bind to fibers of connective tissues, such as collagen (KIERNAN, 1981). In the mouse embryos, the perichondral layer of connective tissue (e.g. surrounding the ribs) consistently stained more intensely (Figs 5A, 6C, 7D). In zebrafish, the myoseptal connective tissue sheets and ligaments also stained very well with PMA (Fig. 8D). On the other hand, the epidermal epithelia in the mouse embryos stained more intensely than the collagen-rich dermal layer. Although several epithelial structures showed a high affinity for all three of the contrast agents, PTA and PMA have been shown to enable consistent visualization of collagenous tissue. Also muscle tissue stained consistently well, especially in the tadpoles and zebrafish with fully-differentiated muscle fibers (Figs 6, 8). In both, the individual fibers could be visualized. Similar levels of details have been obtained using $\mathrm{OsO}_{4}$ in mouse tongue muscles (AOYAGI et al., 2013), and with $\mathrm{I}_{2} \mathrm{KI}$ in crocodile and mouse cranial muscles (JEFFERY et al., 2011; TSAi \& Holliday, 2011; GignaC \& Kley, 2014). Also heart muscle tissue was clearly visible in our PTA and PMA specimens. The heart is mainly composed of cardiac muscle cells, embedded within a network of collagen-rich connective tissue in the extracellular space of the myocardium (WEBER et al., 1994). This, together with the thin endomysial layer of connective tissue, may explain the high affinity for PMA.

For all contrast agents tested, blood and liver stained at high intensities in a consistent manner (see above). Also consistent, both in staining and moderate intensity level, was the visualization of epithelial structures using PMA and PTA. Especially the olfactory, digestive, respiratory and integumentary epithelia (follicles of vibrissae) 
were always prominently visible, in all specimens and taxa studied. Also glandular structures could be identified in both PTA and PMA, but were most prominent in the PMA specimens.

Cartilage stained moderately with PMA and PTA in all three taxa studied. Similar results were obtained by METSCHER (2009a). In Xenopus tadpoles, individual chondrocytes could be visualized (Fig. 6C), whereas in the mouse embryos it was the matrix that showed $\mathrm{X}$-ray attenuation. This is in concordance with what METSCHER (2009a) found after staining fish specimens with PTA. GOLDING et al. (2007) showed a high affinity of PMA for the surrounding soft tissues of mollusk cartilages, where the matrix itself did not stain.

\section{Tissue/organ discrimination dependent on penetration potentials?}

The capacities of these agents to visualize soft tissues in larger specimens can be expected to be inversely related to their potential to penetrate tissues (larger molecules have higher attenuation but penetrate less well). However, PAUWELS et al. (2013) quantified penetration rates of 12 different contrast agents, showing that the relation is not that simple. A correlation analysis done on the atomic number and penetration rate (data from table 1 and 2 of that study, penetration rate calculated from the $24 \mathrm{~h}$ data in table 2) actually showed a positive correlation (Pearson correlation coefficient of $0.73, \mathrm{p}=0.02$ ). In that study, the samples (mice paws) were already fully stained after 24 hours of staining with iodine (KI), whereas PMA showed the slowest penetration rate (of $\mathrm{OsO}_{4}$, PMA and PTA). As the authors indicated, other factors, such as concentration of the contrast solution, solvent, tissue composition and pretreatment protocols will also have played a role in these penetration rates. In our study, pretreatment tissue composition was kept constant with the mouse embryos, as was to some degree the concentration. However, controlling for the other factors remains practically impossible.
Osmium, which was not included in the latter study, has an atomic number that is slightly heavier than that of tungsten (76 vs 74), and substantially higher than that of molybdenum (42). For application in mouse embryos, it was even advised to remove the epithelial layers prior to staining (JOHNSON et al., 2006). Although this was not performed in our study (and in both studies, specimens were kept in a $1 \%$ osmium solution overnight), the $\mathrm{OsO}_{4}$ was shown to have homogenously penetrated throughout the specimen. Also, specimens used by JOHNSON et al. (2006) were even slightly younger, and hence smaller than the ones used in our study. AOYAGI et al. (2010) stained E13 stage mouse for 24h in a $1 \%$ osmium solution, obtaining better contrast than we did in our study. Previous studies had already shown that the penetration speed depends on the tissue density, and that the diffusion rate depends on the $\mathrm{OsO}_{4}$ concentration (BURKL \& SCHIECHL, 1968). It is therefore suggested that a higher concentration and a longer duration of treatment with $\mathrm{OsO}_{4}$ would resolve the problem of low contrast, and increase the intensity of the overall staining. The quality of a staining is also dependent on other factors, such as the embedding procedure.

Penetration of PTA has been reported to be much slower than that of iodine (METSCHER, 2009b). Unlike inorganic iodine ( $\mathrm{I}_{2} \mathrm{KI}$ or $\left.\mathrm{I}_{2} \mathrm{E}\right)$, PTA is a larger molecule (KEGGIN, 1934), which requires a longer incubation to penetrate deeply into the specimens. The longer incubation period (i.e. six days) for PMA in our study, in contrast to the shorter incubation period (i.e. overnight) for the other contrast agents, may thus also explain the better results observed with PMA. Further testing of the effect of incubation times on tissuespecific contrasting and color value heterogeneity in voxel data could clarify this issue.

As mentioned previously, Lugol's iodine $\left(\mathrm{I}_{2} \mathrm{KI}\right)$ is a much smaller molecule and it is known to diffuse rapidly and deeply into fixed tissues (METSCHER, 2009a, b). DEGENHARDT et al. (2010) also showed that it better penetrates and stains soft tissues. One should, however, 
also consider the artefacts being induced, as shrinkage and tissue distortions were observed with higher iodine concentrations, showing an inherent trade-off between contrast and tissue preservation (DEGENHARDT et al., 2010; VICKERTON et al., 2013). However, GignAC \& KLEY (2014) showed optimal incubation times in Lugol's iodine of two weeks for larger specimens, without the extensive shrinkage reported by VICKERTON et al. (2013). Whether or not shrinkage was also induced by the other staining agents, was not apparent but was also not quantified.

\section{CONCLUSIONS}

In conclusion, this study provides further insight into the potential of contrast agents for soft tissue discrimination in $\mu \mathrm{CT}$ voxel data. We were able to demonstrate that $\mathrm{OsO}_{4}$, PTA and PMA provide moderate to very good contrast among tissue and organ structures, both in mouse embryos and in other vertebrates. In our study, PTA and PMA proved to be suitable, less-toxic alternatives to $\mathrm{OsO}_{4}$. Especially PMA consistently yielded very good results, which could partially be explained by the longer incubation time applied. Most agents stained certain tissue types or organs more intensely in a rather consistent manner (e.g. liver, lungs, cell-dense brain regions, epithelial structures), whereas other tissue and organ types could be distinguished based on a moderate contrast, combined with their topography with respect to other organs. Further studies would be needed to quantify contrasting potentials of these agents for tissue types, in relation to, for example, incubation time. Based on the information obtained, we further confirmed the substantial potential for these contrast agents to allow detailed 3D anatomical analysis using $\mu \mathrm{CT}$ scanning.

\section{ACKNOWLEDGEMENTS}

This work was supported by the Concerted Research Actions (GOA - 01G01908) of Ghent
University. The Fund for Scientific Research Flanders (FWO) is acknowledged for the doctoral grant to D. Van Loo (G.0100.08). The authors thank the Department for Molecular Biomedical Research (DMBR) of the University Ghent for providing the mouse embryos and Xenopus tadpoles.

\section{REFERENCES}

ALLEN INSTITUTE FOR BRAIN SCIENCE. (2014). "Allen mouse brain atlas." from http://mouse. brain-map.org.

AOYAGI H, IWASAKI SI \& NAKAMURA K (2013). Three-dimensional observation of mouse tongue muscles using micro-computed tomography. Odontology.

Aoyagi H, TSuchikawa K \& IWASAKI S (2010). Three-dimensional observation of the mouse embryo by micro-computed tomography: Composition of the trigeminal ganglion. Odontology 98(1): 26-30.

BARON RL (1994). Understanding and optimizing use of contrast material for ct of the liver. American Journal of Roentgenology 163(2): 323-331.

BATENBURG JJ \& HAAGSMAN HP (1998). The lipids of pulmonary surfactant: Dynamics and interactions with proteins. Progress in Lipid Research 37(4): 235-276.

BAVERSTOCK H, JeFFERY NS \& COBB SN (2013). The morphology of the mouse masticatory musculature. Journal of Anatomy 223(1): 46-60.

Betz O, Wegst U, Weide D, HeEthoff M, Helfen L, LeE WAHK \& Cloetens P (2007). Imaging applications of synchrotron $\mathrm{x}$-ray phase-contrast microtomography in biological morphology and biomaterials science. I. General aspects of the technique and its advantages in the analysis of millimetre sized arthropod structure. Journal of Microscopy 227(1): 51-71.

Bock WJ, SHEAR, R.C. (1972). A staining method for gross dissection of vertebrate muscles. Anat. Anz.Bd. 130: 222-227.

Boistel R, Swoger J, Kržič U, Fernandez V, GILlET B \& REYNAUd EG (2011). The future of three-dimensional microscopic imaging in marine biology. Marine Ecology 32(4): 438-452.

Brunelli E, Perrotta E \& Tripepi S (2004). Ultrastructure and development of the gills in rana 
dalmatina (amphibia, anura). Zoomorphology 123(4): 203-211.

BURKL W \& SCHIECHL H (1968). A study of osmium tetroxide fixation. Journal of Histochemistry \& Cytochemistry 16(3): 157-161.

Buytaert J, Descamps E, AdRiAENS D \& DiRCKX JJJ (2012). The opfos microscopy family: Highresolution optical-sectioning of biomedical specimens. Anatomy Research International 2012: 9 pages.

CARDENA, RAJACHAR RM, MORRIS MD \& KOHN DH (2003). Ultrastructural changes accompanying the mechanical deformation of bone tissue: A raman imaging study. Calcif. Tissue Int. 72: 166-175.

CARSON FL \& HLADIK C (2009). Histotechnology: A self-instructional text. American Society for Clinical Pathology Press, Hong Kong.

ChEng K. (2013). "Zebrafish atlas." 2014, from http://zfatlas.psu.edu/.

Cnudde V, Boone M, Dewanckele J, Dierick M, VAN HoOREBEKE L \& JACOBS P (2011). 3d characterization of sandstone by means of $x$-ray computed tomography. Geosphere 7(1): 54-61.

CONDON JC, JeYASURIA P, FAUST JM \& MENDELSON CR (2004). Surfactant protein secreted by the maturing mouse fetal lung acts as a hormone that signals the initiation of parturition. PNAS 101(14): 4978-4983.

COX PG \& JEFFERY N (2011). Reviewing the morphology of the jaw-closing musculature in squirrels, rats, and guinea pigs with contrastenhanced microct. Anatomical Record-Advances in Integrative Anatomy and Evolutionary Biology 294(10): 915-928.

DegenhardT K, Wright AC, Horng D, PADMANABHAN A \& EPSTEIN JA (2010). Rapid $3 \mathrm{~d}$ phenotyping of cardiovascular development in mouse embryos by micro-ct with iodine staining. Circulation: Cardiovascular Imaging 3(3): 314322.

Descamps E, Buytaert J, De Kegel B, Dirckx J $\&$ ADRIAENS D (2012). A qualitative comparison of $3 \mathrm{~d}$ visualization in xenopus laevis using a traditional method and a non-destructive method. Belgian Journal of Zoology 142(2): 101-113.

Di ScIPIO F, RAIMONDO S, Tos P \& GEUNA S (2008). A simple protocol for paraffin-embedded myelin sheath staining with osmium tetroxide for light microscope observation. Microscopy Research and Technique 71(7): 497-502.
Dierick M, Van Loo D, Masschaele B, Boone M \& VAN Hoorebeke L (2010). A labview ${ }^{\circledR}$ based generic ct scanner control software platform. Journal of X-Ray Science and Technology 18(4): 451-461.

DOBRIVOJEVIC M, BOHACEK I, ERJAVEC I, GORUP D \& GAJOVIC S (2013). Computed microtomography visualization and quantification of mouse ischemic brain lesion by nonionic radio contrast agents. Croatian Medical Journal 54(1): 3-11.

EFImova OI, KHLEBNiKov AS, SENIN RA, Voronin PA \& ANOKHIN KV (2013). Contrasting of biological samples for $\mathrm{X}$-ray synchrotron microtomography. Bulletin of Experimental Biology and Medicine 155(4): 413-416.

Fishman EK, Ney DR, HeAth DG, CORL FM, HORTON KM \& JOHNSON PT (2006). Volume rendering versus maximum intensity projection in ct angiography: What works best, when, and why1. Radiographics 26(3): 905-922.

GignAC PM \& KLEY NJ (2014). Iodine-enhanced micro-ct imaging: Methodological refinements for the study of the soft-tissue anatomy of postembryonic vertebrates. J Exp Zool B Mol Dev Evol 322(3): 166-176.

GOLDING RE \& JONES AS (2007). Micro-ct as a novel technique for $3 \mathrm{~d}$ reconstruction of molluscan anatomy. Molluscan Research 27: 123-128.

HALL,C, JAKUS M \& SCHMITT F (1945). The structure of certain muscle fibrils as revealed by the use of electron stains. Journal of Applied Physics 16: 459-465.

HARDY RJ \& FRIEDRICH VL, JR. (1996). Oligondendrocyte progenitors are generated throughout the embryonic mouse brain, but differentiate in restricted foci. Development 122: 2059-2069.

HAYAT MA (2000). Principles and techniques of electron microscopy: Biological applications. Cambridge University Press. p.564.

ISOGAI S, HORIGUCHI M \& WEINSTEIN BM (2001). The vascular anatomy of the developing zebrafish: An atlas of embryonic and early larval development. Developmental Biology 230(2): 278-301.

JefFery NS, StePHENSON RS, Gallagher JA, JARVIS JC \& COX PG (2011). Micro-computed tomography with iodine staining resolves the arrangement of muscle fibres. J Biomech 44(1): 189-192. 
JOHNSON JT, HANSEN MS, WU I, HEALY LJ, JOHNSON CR, JONes GM, CAPECCHI MR \& Keller C (2006). Virtual histology of transgenic mouse embryos for high-throughput phenotyping. Plos Genetics 2(4): 471-477.

Jones AS, Milthorpe BK \& Howlett CR (1994). Measurement of microtomy induced section distortion and its correction for 3-dimensional histological reconstructions. Cytometry 15: 95105.

KeGGiN J (1934). The structure and formula of 12-phosphotungstic acid. Proceedings of the Royal Society of London. Series A 144(851): 75100.

KIERNAN JA (1981). Histological and histochemical methods. Theory and practice. Pergamon Press, Oxford.

KNUDSON CB \& KNUDSON W (2001). Cartilage proteoglycans. Cell \& Development Biology, Elsevier.

LECKER DN, KUMARI S \& KHAN A (1997). Iodine binding capacity and iodine binding energy of glycogen. Journal of Polymer Science Part A: Polymer Chemistry 35(8): 1409-1412.

MA S, Charron J \& ERIKSON RL (2003). Role of plk2 (snk) in mouse development and cell proliferation. Molecular and Cellular Biology 23(19): 6936-6943.

Masschaele BC, CNUdde V, Dierick M, Jacobs P, VAN HoOREBEKE L \& VlasSENBROECK J (2007). Ugct: New x-ray radiography and tomography facility. Nuclear Instruments and Methods in Physics Research Section A: Accelerators, Spectrometers, Detectors and Associated Equipment 580(1): 266-269.

METSCHER BD (2009a). Microct for comparative morphology: Simple staining methods allow highcontrast $3 \mathrm{~d}$ imaging of diverse non-mineralized animal tissues. BMC Physiol 9: 11.

MEtscher BD (2009b). Microct for developmental biology: A versatile tool for high-contrast $3 \mathrm{~d}$ imaging at histological resolutions. Developmental Dynamics 238(3): 632-640.

MiZUTANI R \& SUZUKI Y (2012). X-ray microtomography in biology. Micron 43(2-3): 104-115.

Mizutani R, TAKeuchi A, Uesugi K, TAKeKoshi S, OSAMURA RY \& SUZUKI Y (2008). X-ray microtomographic imaging of three-dimensional structure of soft tissues. Tissue Engineering Part C-Methods 14(4): 359-363.

Naveh GR, BRumfeld V, Dean M, Shahar R \& WEINER S (2014). Direct microct imaging of nonmineralized connective tissues at high resolution. Connect Tissue Res 55(1): 52-60.

PATTON JT \& KAUFMAN MH (1995). The timing of ossification of the limb bones, and growth-rates of various long bones of the fore and hind limbs of the prenatal and early postnatal laboratory mouse. Journal of Anatomy 186: 175-185.

Paunels E, Van Loo D, Cornillie P, Brabant L \& VAN HoOREBEKe L (2013). An exploratory study of contrast agents for soft tissue visualization by means of high resolution x-ray computed tomography imaging. Journal of Microscopy 250(1): 21-31.

Pohlmann A, Möller M, Decker H \& Schreiber WG (2007). Mri of tarantulas: Morphological and perfusion imaging. Magnetic Resonance Imaging 25(1): 129-135.

Quintarelli G, Zito R \& Cifonelli J (1971). On phosphotungstic acid staining. I. Journal of Histochemistry \& Cytochemistry 19(11): 641647.

RITMAN EL (2004). Micro-computed tomographycurrent status and developments. Annual Review of Biomedical Engineering 6: 185-208.

RitMAN EL (2011). Current status of developments and applications of micro-ct. Annual Review of Biomedical Engineering, Vol 13 13: 531-552.

ROY MC, NAKANISHI H, TAKAHASHI K, NAKANISHI $\mathrm{S}$, Kajthara S, HayasaKa T, Setou M, Ogawa K, TAguchi R \& Naito T (2011). Salamander retina phospholipids and their localization by maldi imaging mass spectrometry at cellular size resolution. Journal of Lipid Research 52(3): 463470.

Rubin GD, DAKe MD, NAPEL S, JeFFRey RB, MCDONNELl CH, SOMMER FG, WeXLER L \& WiLliams DM (1994). Spiral ct of renal artery stenosis: Comparison of three-dimensional rendering techniques. Radiology 190(1): 181-189.

SANTI PA (2011). Light sheet fluorescence microscopy: A review. Journal of Histochemistry \& Cytochemistry 59(2): 129-138.

SCHAMBACH SJ, BAG S, Schilling L, GRODEN C \& BROCKMANN MA (2010). Application of micro-ct in small animal imaging. Methods 50(1): 2-13. 
SCHAMBRA U (2008). Prenatal mouse brain atlas. Springer Science+Business Media, LLC, New York.

Seki T, SaWamoto K, Parent JM \& AlvarezBUYLlA A (2011). Neurogenesis in the adult brain in Neurobiology. Springer, Tokyo.

Sharpe J, Ahlgren U, Perry P, Hill B, Ross A, HECKSHER-SORENSEN J, BALDOCK R \& DAVIDSON D (2002). Optical projection tomography as a tool for $3 \mathrm{~d}$ microscopy and gene expression studies. Science 296(5567): 541-545.

STOCKWELL RA (1979). Biology of cartilage cells. Cambridge University Press.

TSAI HP \& HollidaY CM (2011). Ontogeny of the alligator cartilago transiliens and its significance for sauropsid jaw muscle evolution. Plos One 6(9):e24935. https://doi.org/10.1371/journal. pone. 0024935

TUCKER AS (2007). Salivary gland development. Seminars in Cell \& Developmental Biology 18(2): 237-244.

TYSZKA JM, FRASER SE \& JACOBS RE (2005). Magnetic resonance microscopy: Recent advances and applications. Current Opinion in Biotechnology 16(1): 93-99.

Ullmann JF, COWIN G, KuRNiaWAN ND \& COLlin SP (2010). A three-dimensional digital atlas of the zebrafish brain. Neuroimage 51(1): 76-82.

VICKERTON P, JARVIS J \& JEFFERY N (2013). Concentration-dependent specimen shrinkage in iodine-enhanced microct. J Anat 223(2): 185-193.

Vlassenbroeck J, Dierick M, Masschaele B, Cnudde V, Van HoorebeKe L \& Jacobs $P$ (2007). Software tools for quantification of $\mathrm{x}$-ray microtomography. Nuclear Instruments \& Methods in Physics Research Section a-Accelerators Spectrometers Detectors and Associated Equipment 580(1): 442-445.

Warburton D, El-Hashash A, Carraro G, Tiozzo C, Sala F, Rogers O, De Langhe S, KEMP PJ, RicCARDI D, TORDAY J, BELlusci S, SHI W, LUBKIN SR \& JESUDASON E (2010). Lung organogenesis. Organogenesis in Development 90: 73-158.

Watling C, LAGo N, Benmerah S, FitzGerald J, TARTE E, MCMAHON S, LACOUR S \& CAMERON $R$ (2010). Novel use of x-ray micro computed tomography to image rat sciatic nerve and integration into scaffold. Journal of Neuroscience Methods 188(1): 39-44.
WATSON ML (1958). Staining of tissue sections for electron microscopy with heavy metals. The Journal of Biophysical and Biochemical Cytology 4(4): 475-478.

Weber KT, Sun Y, Tyagi SC \& Cleutjens JPM (1994). Collagen network of the myocardium: Function, structural remodeling and regulatory mechanisms. Journal of Molecular and Cellular Cardiology 26(3): 279-292.

WIECHMANN AF \& WIRSIG-WIECHMANN CR (2003). Color atlas of xenopus laevis histology. Kluwer Academic Publishers, Boston.

WigGLESWORTH V (1975). Lipid staining for the electron microscope: A new method. Journal of Cell Science 19(3): 425-437.

Wilhelm G, HANDSCHUH S, Plant J \& NEMESCHKAL HLEO (2011). Sexual dimorphism in head structures of the weevil rhopalapion longirostre (olivier 1807) (coleoptera: Curculionoidea): A response to ecological demands of egg deposition. Biological Journal of the Linnean Society 104(3): 642-660.

WiRSÉN C \& LARSSON KS (1964). Histochemical differentiation of skeletal muscle in foetal and newborn mice. Journal of Embryology and Experimental Morphology 12: 758-767.

WULLimANn MF, RupP B \& REICHERT H (1996). Neuroanatomy of the zebrafish brain: A topological atlas. Birkhäuser Verlag, Basel.

Zanette I, Daghfous G, WeitKamp T, Gillet B, Adriaens D, LANGer M, Cloetens P, Helfen L, Bravin A, Peyrin F, Baumbach T, Dischler J-M, VAN LoO D, Praet T, PoIRIER-Quinot M \& BOISTEL R (2013). Looking inside marine organisms with mri and x-ray tomography. In: Reynaud EG (Eds.). Imaging marine life. Wiley \& Sons: $123-186$.

Received: March 12th, 2014

Accepted: April 25th, 2014

Branch editor: Isa Schön 